\title{
ANALISIS KINERJA INTERPERSONAL RELATIONSHIP TERHADAP CUSTOMER LOYALTY (Survei pada Pelanggan Telkom Speedy di Kota Bandung)
}

\author{
Khelvin Aidil Fitriansyah \\ Universitas Pendidikan Indonesia \\ khelvin.aidil@student.upi.edu \\ Ratih Hurriyati \\ Universitas Pendidikan Indonesia \\ ratihhurriyati@upi.edu
}

\begin{abstract}
ABSTRAK
Persaingan bisnis secara global untuk meningkatkan pertumbuhan ekonomi di dunia membuat suatu perusahaan harus memproduksi barang maupun jasa yang mempunyai kualitas sangat bagus agar pelanggan bertahan mengonsumsi produk maupun jasa. Dalam hal memberikan pelayanan yang terbaik kepada pelanggan di era kompetisi ini, harga produk tidak lagi mutlak menjadi faktor penentu bagi pelanggan dalam memilih sebuah produk. Kualitas produk dan layanan merupakan hal penting yang harus menjadi perhatian operator telekomunikasi. Hal tersebut juga diterapkan oleh PT Telekomunikasi Indonesia Tbk dengan strategi pelayanan terbaik melalui produknya yaitu Telkom Speedy. Penelitian ini bertujuan untuk mengetahui kinerja interpersonal relationship pada pelanggan Telkom Speedy di Kota Bandung, memperoleh deskripsi customer loyalty pada pelanggan Telkom Speedy di Kota Bandung dan mengetahui kinerja interpersonal relationship terhadap customer loyalty pada pelanggan Telkom Speedy di Kota Bandung. Jenis penelitian yang digunakan adalah deskriptif verifikatif, dan metode yang digunakan adalah explanatory survey dengan teknik simple random sampling dengan jumlah sampel 110 responden. Teknik analisis data yang digunakan adalah regresi linear sederhana dengan alat bantu software komputer SPSS 22.0. Berdasarkan hasil penelitian terhadap pengujian hipotesis dapat diketahui bahwa interpersonal relationship memiliki pengaruh yang positif terhadap customer loyalty.
\end{abstract}

Kata Kunci : Interpersonal Relationship, Customer Loyalty

\section{PENDAHULUAN}

Loyalitas pelanggan penting artinya bagi perusahaan yang menjaga kelangsungan usahanya maupun kelangsungan kegiatan usahanya. Pelanggan yang setia adalah mereka yang sangat puas dengan produk dan pelayanan tertentu, sehingga mempunyai antusiasme untuk memperkenalkannya kepada siapapun yang mereka kenal. Selanjutnya pada tahap berikutnya pelanggan yang loyal tersebut akan memperluas "kesetiaan" mereka pada produk-produk lain buatan produsen yang sama. Dan pada akhirnya mereka adalah konsumen yang setia pada produsen atau perusahaan tertentu untuk selamanya.

Gitomer (2011:98) menyatakan bahwa tantangan terbesar bagi perusahaan bukan menghasilkan pelanggan yang puas karena pesaing dapat melakukan hal tersebut, melainkan menghasilkan pelanggan yang senang dan setia. Griffin (2005:31) mengidentifikasi terdapat empat macam dimensi loyalitas konsumen yaitu makes regular repeat purchase, immunity, refers other, dan purchase across product and service line.

Kualitas produk dan layanan merupakan hal penting yang harus menjadi perhatian tiap perusahaan agar keberlangsungan hidupnya terjamin. Pengaruh globalisasi memiliki dampak terhadap hal tersebut sehingga yang diuntungkan dari hal ini adalah masyarakat atau konsumen. Kebutuhan konsumen dapat terpenuhi dan bahkan memiliki lebih banyak alternatif dalam penentuan produk untuk memenuhi kebutuhannya. Kompetisi antara perusahaan semakin berat, oleh karena itu perusahaan berupaya untuk mempertahankan pelanggan yang sudah ada maka dibuatlah program-program loyalitas pelanggan.

Hal tersebut memiliki peran penting dalam sebuah perusahaan, mempertahankan konsumen berarti meningkatkan kinerja keuangan dan mempertahankan keberlangsungan hidup perusahaan. Dua hal yang menjadi pertimbangan utama perusahaan dalam mempertahankan loyalitas pelanggan adalah pertama karena semakin mahalnya biaya perolehan pelanggan baru seiring dengan tingginya tingkat persaingan, kedua adalah adanya kenyataan bahwa tingkat profitabilitas perusahaan berbanding lurus dengan pertumbuhan hubungan antara perusahaan dan pelanggan secara permanen. Oleh karena hal tersebut, perusahaan mulai mengubah pola pikir dari orientasi keuntungan kearah faktor-faktor 
potensial lainnya seperti kepentingan pelanggan dan tingkat kepuasan pelanggan menjadi faktor utama yang harus diperhatikan oleh perusahaan. Dalam dunia bisnis baru lingkup perusahaan hal tersebut dinamakan dengan customer relationship management.

Alasan mendasar yang mendorong perusahaan membina hubungan dengan konsumen sesungguhnya sangat klasik, yakni motif ekonomi. Pundi-pundi perusahaan akan semakin membesar manakala mampu mengelola baseline konsumen untuk mengidentifikasi, memuaskan, dan berhasil mempertahankan konsumen mereka yang paling menguntungkan. Dalam customer relationship management, hubungan interpersonal sangat penting dan dibutuhkan untuk memberikan kesuksesan kepada perusahaan. Di dalam dunia bisnis baik barang ataupun jasa tidaklah henti-hentinya melakukan persaingan untuk membuat konsumennya tetap setiap kepada barang atau jasa yang ditawarkan dan tidak berpaling pada produk yang lain.

Hubungan interpersonal sebagai konsep yang menggambarkan koneksi atau jaringan, dan ini melibatkan kewajiban timbal balik dan keuntungan antara dua pihak dalam hubungan pribadi atau bisnis. (Liu dan Wang: 2009)

Penelitian yang dilakukan oleh Crosby (2000) menunjukkan bahwa kualitas hubungan pelanggan dengan penjual atau perusahaan mempengaruhi harapan pelanggan melakukan interaksi masa depan dengan penjual atau perusahaan dalam jangka panjang. Adapun yang dikemukakan oleh Heidarzadeh (2006) bahwa komunikasi antara individu karyawan dan pelanggan sama-sama berdampak pada kepuasan serta tingkat loyalitas pelanggan. Menurut Peter (2014:212), interpersonal relationship memiliki beberapa dimensi yaitu interpersonal communication, relational style, relational atmoshphere, dan friendly interactions.

Pada tahun 2009 hingga 2014 terjadi kenaikan dalam jumlah pelanggan yang berlangganan Telkom Speedy. Namun, jumlah pelanggan yang berhenti berlangganan Telkom Speedy berbanding lurus dengan jumlah pelanggan. Dengan memberikan koneksi ke internet yang lebih cepat dibanding menggunakan layanan dial-up seharusnya menjadikan Telkom Speedy unggul serta memunculkan daya tarik tersendiri. Terlebih PT Telekomunikasi Indonesia, Tbk. telah merancang portofolio bisnis baru yaitu TIMES (Telecommunication, Information, Media, Edutainment, dan Service) dimana layanan menjadi nilai tambah dari portofolio sebelumnya. Sehingga layanan yang seharusnya diberikan kepada pelanggannya harus lebih baik dari sebelumnya. Hubungan yang kuat antara pelanggan dengan perusahaan sangat dibutuhkan agar memunculkan loyalitas pelanggan. Dengan cara melakukan hubungan interpersonal atau interpersonal relationship maka perusahaan dapat memiliki banyak pelanggan yang loyalitas terhadap penggunaan produknya.

Penelitian ini sifatnya melanjutkan penelitian yang sudah dilakukan sebelumnya. Adapun perbedaan dengan penelitian-penelitian sebelumnya yaitu pada fenomena masalah. Penelitian mengenai interpersonal relationship banyak dilakukan pada pelayanan hotel, pariwisata, dan restoran. Karena bisnis pelayanan jasa biasanya membuat perusahaan melalui karyawannya dekat dengan pelanggan. Pada penelitian ini, akan dilakukan penelitian interpersonal relationship pada pelanggan internet provider.

Berdasarkan dari uraian permasalahan yang telah dikemukakan, maka perlu dilakukan penelitian mengenai "Analisis Kinerja Interpersonal Relationship terhadap Customer Loyalty" (Survei pada Pelanggan Telkom Speedy di Kota Bandung)

Adapun tujuan penelitian untuk mengetahui kinerja interpersonal relationship pada pelanggan Telkom Speedy di Kota Bandung, memperoleh deskripsi customer loyalty pada pelanggan Telkom Speedy di Kota Bandung dan mengetahui kinerja interpersonal relationship terhadap customer loyalty pada pelanggan Telkom Speedy di Kota Bandung.

\section{METODE PENELITIAN}

Unit analisis yang dijadikan responden dalam penelitian ini adalah pelanggan Telkom Speedy di Kota Bandung. Oleh karena itu akan diteliti analisis kinerja interpersonal relationship terhadap customer loyalty pada pelanggan Telkom Speedy di Kota Bandung. Penelitian ini dilakukan dalam kurun waktu kurang dari satu tahun, maka metode yang digunakan adalah cross sectional method, pengumpulan informasi dari subjek penelitian hanya dilakukan satu kali dalam satu periode waktu, sehingga penelitian ini merupakan one-shot atau cross sectional. Penelitian ini dilakukan pada bulan September Desember 2015.

Populasi dalam penelitian ini adalah seluruh pelanggan Telkom Speedy di Kota Bandung pada tahun 2015 sebanyak N: 102.678 pelanggan. Pengambilan sampling menggunakan simple random sampling dari jumlah populasi dan dengan menggunakan rumus Harun AlRasyid diperoleh sampel sebanyak 110 pelanggan. 


\section{HASIL PENELITIAN \\ Uji Normalitas}

Hasil perhitungan linearitas terdapat pada Tabel berikut ini.

TABEL 4.14

UJI NORMALITAS One-Sample Kolmogorov-Smirnov Test

\begin{tabular}{|ll|r|}
\hline & & $\begin{array}{c}\text { Unstandar } \\
\text { dized } \\
\text { Predicted } \\
\text { Value }\end{array}$ \\
\hline $\mathrm{N}$ & Mean & 110 \\
Normal & Std. & 99.709090 \\
Parameters $^{\text {a,b }}$ & Deviation & 9 \\
Most Extreme & Absolute & .114 \\
Differences & Positive & .060 \\
Kolmogorov-Smirnov Z & -.114 \\
Asymp. Sig. (2-tailed) & 1.195 \\
\hline
\end{tabular}

a. Test distribution is Normal.

b. Calculated from data.

Berdasarkan Tabel 1.1 menunjukkan bahwa hasil uji normalitas dengan KolmogorovSmirnof Test diperolej nilai KSZ sebesar 1,195 Asymp. Sig. sebesar 0,115 atay > 0,05 maka dapat disimpulkan data tersebut berdistribusi normal.

Setelah diketahui bahwa variabel interpersoal relationship dan variabel customer loyalty berdistribusi normal, maka selanjutnya perlu diketahui apakah kedua variabel tersebut benar-benar memiliki hubungan linear, untuk itu perlu dilakukan uji linearitas regresi variabel $\mathrm{X}$ atas variabel Y. Hasil analisis data diperoleh output Anova pada Tabel 4.15 sebagai berikut.

\section{TABEL 4.15}

\section{UJI LINEARITAS}

\begin{tabular}{|c|c|c|c|c|c|c|}
\hline \multicolumn{7}{|c|}{ ANOVA: } \\
\hline Model & & Sum of Squares & df & Mean Square & $\mathrm{F}$ & Sig. \\
\hline \multirow{3}{*}{1} & Regression & 9442.058 & 1 & 9442.058 & 165.257 & $.000^{\circ}$ \\
\hline & Residual & 6170.632 & 108 & 57.135 & & \\
\hline & Total & 15612.691 & 109 & & & \\
\hline \multicolumn{7}{|c|}{ a. DependentVariable: Customer Loyalty } \\
\hline \multicolumn{7}{|c|}{ b. Predictors: (Constant), Interpers onal Relations hip } \\
\hline & $\mathrm{Be}$ & asarkan & & asil & pe & ujian \\
\hline
\end{tabular}

menggunakan uji $\mathrm{F}_{\text {test }}$ didapatkan $\mathrm{F}_{\text {hitung }}$ sebesar 165,257 dengan tingkat signifikansi $0,000 \leq 0,05$ artinya variabel interpersonal relationship (X) secara keseluruhan model tersebut sudah fit dan terdapat hubungan antara variabel interpersonal relationship terhadap customer loyalty sehingga regresi bisa dipakai untuk memprediksi loyalitas pelanggan. Berdasarkan hasil pengujian Linearitas, maka dapat dikatakan bahwa data yang dihasilkan memenuhi asumsi Linearitas.
Untuk melihat lebih jelas mengenai linearitas data tersebut, dapat dilihat dalam grafik Scatter-Plot pada Gambar 4.5 berikut.

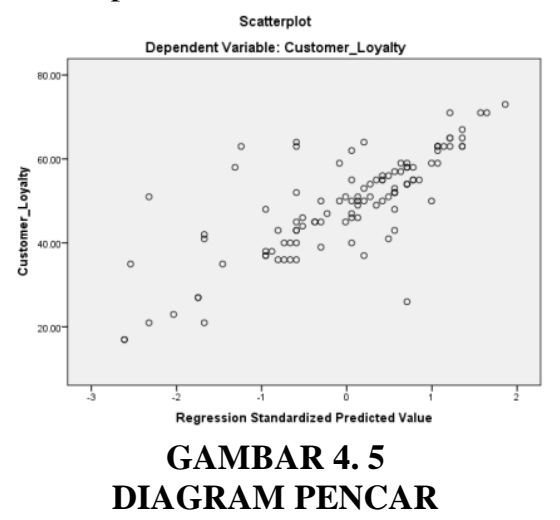

Pada Gambar 4.5 menggambarkan bahwa titik-titik pada diagram pencar di atas menyebar berbentuk pola dari kiri bawah menuju kanan. Dari garis tersebut dapat diketahui kovaransi antara X dan Y sifatnya searah, dalam arti bahwa apabila $X$ berubah semakin besar maka $Y$ pun berubah semakin besar, hal ini menunjukan bahwa ada hubungan positif antara variabel $\mathrm{X}$ dan Y. Berdasarkan hasil uji asumsi klasik yang telah dilakukan, maka penelitian ini dapat diolah menggunakan analisis regresi liniear sederhana.

\section{Analisis Regresi Linear Sederhana}

Perhitungan persamaan regresi linear sederhana dilakukan dengan menggunakan bantuna software SPSS 22.0 for windows. Hasil perhitungan analisis regresi linear sederhana dapat dilihat dalam Tabel 4.19

TABEL 4. 19 MODEL REGRESI LINEAR SEDERHANA

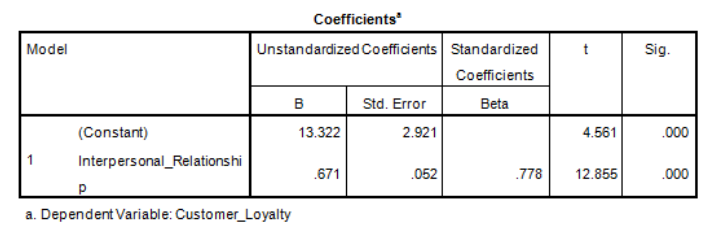

Berdasarkan Tabel 4.19 pada kolom B, tercantum nilai konstanta dan nilai koefisien regresi linear sederhana untuk variabel bebas. Berdasarkan nilai-nilai itu maka dapat ditentukan model regresi linear sederhana yang dinyatakan dalam bentuk persamaan sebagai berikut:

$$
\begin{gathered}
\mathbf{Y}=\mathbf{a}+\mathbf{b X} \\
\mathrm{Y}=13,322+0,671 \mathrm{X}
\end{gathered}
$$

Berdasarkan persamaan regresi linier sederhana di atas, nilai konstanta sebesar 13,322 menyatakan bahwa jika tidak ada interpersonal relationship, maka besarnya customer loyalty sebesar 13,322. Koefisien regresi pada variabel interpersonal relationship adalah 0,671 yang artinya setiap terjadi penambahan nilai interpersonal relationship akan terjadi peningkatan customer loyalty sebesar 0,671. 
Sebaliknya jika terjadi penurunan customer loyalty, interpersonal relationship akan menurunkan customer loyalty sebesar 0,671 satu satuan nilai. Dapat dikatakan bahwa interpersonal relationship yang dibangun oleh perusahaan akan berpengaruh terhadap tingkat loyalitas pelanggan. Jika hubungan interpersonal dirasa gagal oleh pelanggan, maka pelanggan akan berhenti menggunakan produk maupun jasa dari perusahaan atau merek dan berpindah ke produk maupun jasa lainnya.

\section{Uji F}

Untuk menguji signifikansi interpersonal relationship berpengaruh terhadap customer loyalty dapat digunakan uji $\mathrm{F}$, yaitu dengan membandinkan antara $F_{\text {hitung }}$ dan $F_{\text {tabel }}$. Rumus uji $\mathrm{F}$ atau uji ANOVA dijelaskan pada Tabel 4.20 sebagai berikut.

TABEL 4. 20 NILAI SIGNIFIKANSI UJI F

\begin{tabular}{|c|c|c|c|c|c|c|}
\hline Model & & Sum of Squares & df & Mean Square & $\mathrm{F}$ & Sig. \\
\hline \multirow{3}{*}{1} & Regression & 9442.058 & 1 & 9442.058 & 165.257 & $.000^{\circ}$ \\
\hline & Residual & 6170.632 & 108 & 57.135 & & \\
\hline & Total & 15612.691 & 109 & & & \\
\hline
\end{tabular}

Tabel 4.20 menunjukan pengujian untuk uji $\mathrm{F}$ yang diambil dari Anova dengan tingkat probabilitas $(\mathrm{Sig})=0,000$, maka taraf signifikan 0,05 yaitu $0,000 \leq 0,05$. maka keputusan adalah $\mathrm{H}_{\mathrm{o}}$ ditolak. Artinya terdapat pengaruh yang positif dari interpersonal relationship berpengaruh terhadap customer loyalty pelanggan Telkom Speedy di Kota Bandung.

Peneliti juga melakukan pengujian pengaruh variabel bebas secara bersama-sama terhadap variabel terikat dengan menggunakan uji F yaitu $F_{\text {hitung }}>F_{\text {tabel. }}$. Maka $F_{\text {tabel }}$ dengan 110 responden yaitu pada $\mathrm{a}=0,05$ adalah 3,929. Sehingga didapat 165,257>3,929, maka $\mathrm{H}_{\mathrm{o}}$ ditolak. Kesimpulannya sama dengan pengujian yang dilakukan dengan menggunakan nilai probabilitas. Dengan demikian dapat disimpulkan bahwa hipotesis dalam penelitian ini yaitu $\mathrm{H}_{\mathrm{o}}$ ditolak dan $\mathrm{H}_{\mathrm{a}}$ diterima, sehingga terdapat pengaruh antara interpesonal relationship terhadap customer loyalty pada pelanggan Telkom Speedy di Kota Bandung

\section{Koefisien Determinasi}

Untuk mengetahui besarnya persentase pengaruh $\mathrm{X}$ terhadap $\mathrm{Y}$, maka digunakan rumus koefisien determinasi sebagai berikut.

Keterangan:

$\mathrm{r}^{2}=$ koefisien korelasi ( $R$ square $)$

Berikut adalah hasil perhitungan

koefisien determinasi dari $\mathrm{X}$ terhadap $\mathrm{Y}$ :

$\mathrm{KD} \quad=\mathrm{r}^{2} \times 100 \%$

$$
\begin{aligned}
& =r^{2} \times 100 \% \\
& =(0,778)^{2} \times 100 \% \\
& =0,605 \times 100 \% \\
& =60,53 \%
\end{aligned}
$$

Dari hasil penghitungan koefisien determinasi untuk interpersonal relationship (X) terhadap customer loyalty (Y) adalah $60,53 \%$. Dengan kata lain customer loyalty dipengaruhi $60,53 \%$ oleh interpersonal relationship sedangkan $39,47 \%$ dipengaruhi oleh faktorfaktor lainnya diluar interpersonal relationship.

\section{KESIMPULAN DAN REKOMENDASI Kesimpulan}

1. Gambaran mengenai interpersonal relationship Telkom Speedy dapat dilihat dari dimensi-dimensinya yang terdiri dari interpersonal communication, relational style, relational atmosphere dan friendly interaction berada pada kategori cukup tinggi. Hal ini menunjukan bahwa persepsi menurut pelanggan Telkom Speedy di Kota Bandung menilai penerapan Interpersonal Relationship telah berjalan dengan sangat baik. Dimensi relational atmosphere merupakan dimensi yang memiliki penilaian paling tinggi dalam mempengaruhi customer loyalty, sedangkan dimensi yang memiliki penilaian paling rendah dalam mempengaruhi loyalitas pelanggan adalah friendly interaction.

2. Gambaran customer loyalty pada pelanggan Telkom Speedy di Kota Bandung yang diukur berdasarkan repeat purchase, immunity, refers to other, dan purchase across product or service lines secara keseluruhan berada pada kategori cukup tinggi. Artinya penerapan berdasarkan repeat purchase, immunity, refers to other, dan purchase across product or service lines terhadap pelanggan Telkom Speedy di Kota Bandung telah berjalan dengan cukup baik sehingga akan membentuk loyalitas pelanggan yang semakin kuat. Dimensi repeat purchase secara keseluruhan memiliki nilai paling tinggi, sedangkan untuk dimensi yang memiliki nilai terendah adalah purchase across product and service line.

3. Interpersonal Relationship memiliki pengaruh yang positif terhadap Customer Loyalty pelanggan Telkom Speedy di Kota Bandung dengan tingkat korelasi yang kuat sebesar $60,53 \%$, sedangkan untuk pengaruh variabel lain yang tidak diteliti adalah sebesar $39,47 \%$. Hal ini menunjukan bahwa semakin tinggi interpersonal relationship Telkom Speedy maka akan semakin tinggi pula customer loyalty pelanggan Telkom Speedy di Kota Bandung. 


\section{Rekomendasi}

1. Pengaruh faktor interpersonal relationship produk Telkom Speedy di Kota Bandung secara menyeluruh memiliki pengaruh yang signifikan dan dikategorikan cukup baik pengaruhnya terhadap customer loyalty, tetapi ada beberapa yang perlu dilakukan perbaikan yaitu upaya untuk meningkatkan friendly interaction terhadap interpersonal relationship, terutama dalam melayani para pelanggan Telkom Speedy dengan ramah. PT Telekomunikasi Indonesia, Tbk. dapat melakukan pendidikan dan pelatihan kepada para karyawan yang berada pada front office agar dapat melayani pelanggan dengan ramah dan baik lagi. Karena pelanggan akan mempersepsikan bahwa apabila pelanggan berpindah, maka pelanggan tidak akan mendapatkan pelayanan prima dari perusahaan atau produk pesaing lainnya.

2. Customer loyalty pada pelanggan Telkom Speedy di Kota Bandung secara keseluruhan sudah cukup baik, namun hal ini harus dapat dipertahankan bahkan ditingkatkan terutama dalam tingkat menggunakan produk PT Telkom lainnya dengan memberikan berbagai tawaran yang menarik agar konsumen tetap setia terhadap produk Telkom Speedy maupun PT Telekomunikasi Indonesia, Tbk. dan tidak berpindah pada internet provider lain.

3. Hasil penelitian menyatakan ada pengaruh antara interpersonal relationship terhadap customer loyalty, maka penulis merekomendasikan supaya PT Telekomunikasi Indonesia, Tbk. dapat menciptakan dan mengkomunikasikan nilai unggulan produknya dan tetap menjaga, mempertahankan, meningkatkan kembali customer loyalty melalui interpersonal relationship. Salah satu kendala dalam interpersonal relationship adalah kurang baiknya karyawan PT Telekomunikasi Indonesia, Tbk. dalam melayani para pelanggan Telkom Speedy, terutama menanggapi keluhan yang disampaikan oleh pelanggan. Perusahaan perlu mengubah persepsi pelanggan melalui strategi promosi dan peningkatan pelayanan sehingga produk Telkom Speedy memiliki reputasi yang baik dalam benak pelanggan yang dapat menciptakan kelangsungan hidup perusahaan dan dapat meningkatkan pangsa pasarnya.

\section{DAFTAR PUSTAKA}

Al-Rasyid, Harun. (1994). Teknik Penarikan Sampel dan Penyusunan Skala. Bandung : Universitas Padjajaran
Benesbordi, Ali dan Heidary, M. (2012). The Effect of Interpersonal Relationships with Customer's Loyalty in Soccer Schools in Tehran-Iran. International Journal of Academic Research in Business and Social Sciences. 2/1, 278-283

Crosby, Lawrence A., and Kenneth, Evan. (2000). "Relationship Quality in Services Selling: An Interpersonal Influence Perspective". Journal of Marketing, Vol. 54

Griffin, Jill. (2005). Customer Loyalty: Revision Ed. Jakarta: Erlangga

Heidarzadeh, Kambiz Hosseini Firouzabadi. (2006). "Study of Interpersonal Communication and its Impact on Customer Satisfaction and Loyalty to the Service Provider". Islamic Azad University, Tehran Science and Research.

Liu, H. T dan Wang, W. K. (2009). “An Integrated Fuzzy Approach for Provider Evaluation and Selection in Third Party Logistic”. New York: Lexington Book.

Peter, A. Olannye. (2014). "The Effect of Interpersonal Relationship on Marketing Performance in the Nigerian Hotel Industry". International Journal of Business and Social Science: Vol. 5 No. 2; February 2014. Nigeria: Asaba Campus 